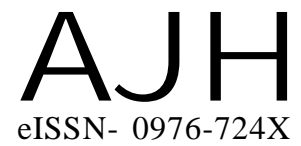

Received : 10.02.2017

Revised : 12.05 .2017

Accepted : 24.05.2017

Author for correspondence: IMTIYAZ AHMAD LONE

Regional Research Station (SKUAST-K) Wadura, SOPORE (J\&K) INDIA
THEASIAN JOURNALOF HORTICULTURE

Volume 12 | Issue $1 \mid$ June, 2017 | 136-140

Visit us -www.researchjournal.co.in

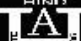

RESEARCH PAPER

DOI : 10.15740/HAS/TAJH/12.1/136-140

\section{Diversity for shell seal in the natural population of walnut (Juglans regia L.) in the Kashmir valley}

\section{IMTIYAZ AHMAD LONE}

ABSTRACT : The present investigation entitled diversity for shell seal in the natural population of walnut (Juglans regia L.) in the Kashmir valley was carried out in order to document the available genetic variability in walnut germplasm and to select elite walnut genotypes possessing superior attributes and quality traits. During the survey, data was recorded on one hundred fifty two (152) walnut trees growing in different areas of Kashmir valley. Remarkable variability was observed in seedling walnut trees for different morphological, nut and kernel characters. Similarly, variations were also reported for other characters viz., tree vigour, growth habit, branching habit, leaflet shape, shoot colour, nut shape, shell texture, shell colour, shell seal, shell strength, shell integrity, kernel shrivel and kernel colour. Studies on shell strangth revealed substantial variability among the seedling raised walnuts genotypes in Kashmir valley revealed that shell seal of walnut genotypes under the present study varied from weak to strong. Forty five genotypes $(29.60 \%)$ were found to have weak shell seal; 60 genotypes $(39.48 \%)$ had intermediate shell seal and 47 genotypes (30.92\%) exhibited strong shell seal.

KEY WORDS : Walnut, Diversity, Shell seal

HOW TO CITE THIS ARTICLE : Lone, Imtiyaz Ahmad (2017). Diversity for shell seal in the natural population of walnut (Juglans regia L.) in the Kashmir valley. Asian J. Hort., 12(1) : 136-140, DOI : 10.15740/HAS/TAJH/12.1/136-140. 